\title{
Study of Brain Imaging in Accelerated Hypertension
}

\author{
Aparna Prasanna Patange1, Pavan Dahyabhai Patel², Shruti Shrinivas Nair ${ }^{3}$, Dahyabhai Muljibhai Patel ${ }^{4}$, Amit Botre $^{5}$ \\ Aditya Ravan', Nitin Jadhav, Tejas Bhosale 8 \\ ${ }^{1}$ Department of Medicine, KIMS, Karad, Maharashtra, India. ${ }^{2}$ Department of Medicine, KIMS, Karad, Maharashtra, \\ India. ${ }^{3}$ Department of Obstetrics and Gynaecology, KIMS, Karad, Maharashtra, India. ${ }^{4}$ Department of Medicine, \\ Vedanta College, Dahanu, Maharashtra, India. ${ }^{5}$ Department of Medicine, KIMS, Karad, Maharashtra, India. \\ ${ }^{6}$ Department of Medicine, KIMS, Karad, Maharashtra, India. ${ }^{7}$ Department of Medicine, KIMS, Karad, Maharashtra, \\ India. ${ }^{8}$ Department of Medicine, KIMS, Karad, Maharashtra, India.
}

\section{ABSTRACT}

\section{BACKGROUND}

Accelerated hypertension is defined as a rapid and inappropriate intense elevation of blood pressure with or without a risk of rapid damage to target organs such as the heart. It is a common presentation to the emergency department and appears without history of hypertensive diseases in $23 \%$ of cases. The present study was conducted to study the brain imaging in cases admitted with accelerated hypertension to find the incidences of brain parenchymal insult in case of accelerated hypertension in a tertiary healthcare institute.

\section{METHODS}

The observational study was done among patients presenting with hypertensive emergencies admitted under the Department of Medicine, KIMS, Karad, from August 2018 to December 2018. On admission, detailed history was taken, and complete clinical examination was done. It was an observational study.

\section{RESULTS}

Majority of the cases had a haemorrhagic stroke (16.66\%), followed by $4.16 \%$ cases of transient ischaemic attacks and $4.16 \%$ cases of ischaemic stroke.

\section{CONCLUSIONS}

Acute intracerebral haemorrhage was the most common form of end organ damage in present study. The hospital mortality among the patients with hypertensive emergencies were $18.75 \%$.

\section{KEY WORDS}

Accelerated Hypertension, Hypertensive Crisis, Brain Imaging, Blood Pressure
Corresponding Author:

Dr. Pavan Dahyabhai Patel, Resident, Department of Medicine, \#17, Girdhardwar Soc. Sec-4, Beside NTTI Nagar Soc, On Bhatra Altnan Canal Road, Bhatra, Surat-395017, Gujarat, India. E-mail:pavan_patel10574@icloud.com

DOI: $10.14260 / j e m d s / 2019 / 794$

Financial or Other Competing Interests: None.

How to Cite This Article:

Patange AP, Patel PD, Nair SS, et al. Study of brain imaging in accelerated hypertension. J. Evolution Med. Dent. Sci. 2019;8(49):3671-3674, DOI: 


\section{BACKGROUND}

Accelerated hypertension is a rapid and excessive high blood pressure elevation with or without a risk of rapid harm to target organs such as the heart.[1]-[3] It is a typical presentation to the emergency department and occurs in 23 percent of patients without history of hypertensive diseases.[4,5]

Among the patients with elevated blood pressure, hypertensive encephalopathy is a neurological condition. It is marked by fast-growing signs and symptoms including nausea, hallucinations, visual disturbances, impaired mental status, and focal neural indications. Although the condition is typically manageable if the hypertension is treated early, if it is not detected and the medication is postponed, it may be lethal. The medical results are not clear enough to make the diagnosis complicated. [6]

Volhard and $\mathrm{F}$ fahr[7] first addressed hypertensive emergency syndrome in 1914 and was characterized by extreme, acute hypertension, along with proofs of renal disease and symptoms of chest, head, retina and kidney coronary damage, with increasingly fatal heart attack, renal insufficiency and stroke. The epidemiology of hypertensive crises parallels the distribution of essential hypertension in the community, being much higher among African-Americans and the elderly; however, men are affected two times more frequently than are women. ${ }^{[8]}$ In 1939, before extensive use of anti-hypertensive agents, the first comprehensive review in natural history with malignant high blood pressure was reported.[9,10] Untreated malignant hypertension was 79 percent one-year mortality and average survival of 10.5 months in this landmark study by Keith and his colleagues.[11]

While HC is uncommon in a clinical trial setting, certain drug interaction research studies, including tyramine in conjunction with monoamine oxidase inhibitors, may cause HC. In addition to the activation of the renin-angiotensin vasopressins system, endothelial and catecholamine are postulated to take important roles in the pathophysiology of the hypertensive emergencies, a quick upward blood pressure in patients with a range of BP from 180/100 to 110 mmHg or a sudden increase in systolic BP above baseline of over $60 \mathrm{mmHg}$.[12]

\section{Clinical Manifestations of Hypertensive Crises}

Hypertensive crisis manifestations clinically involve endorgan dysfunction. Organ dysfunction (excluding in children and during the pregnancy) is uncommon when diastolic pressure is lower than $130 \mathrm{mmHg}$. However, the absolute blood pressure level may not be as significant as the increase rate. A systolic blood pressure of $200 \mathrm{mmHg}$ or up to 150 $\mathrm{mmHg}$ diastolic pressure can be tolerated without development of hypertensive encephalopathy, in patients whose blood pressure has been long lasting, whereas children or pregnant women can develop encephalopathy with a blood pressure of $100 \mathrm{mmHg}$ diastolically.[13,14] Signs and symptoms are different from patient to patient with hypertensive crises. Patients of high-tension encephalopathy exhibit nausea, impaired level of consciousness and/or specific neurological symptoms. These patients may have arteriolar changes, blood cells, exudates, and a papilledema during physical exams.[15] They are retinopathic. Other patients with angina, acute myocardial infarction or acute ventricular failure may experience a cardiovascular manifestation of high blood pressure. In some patients, acute renal failure with oliguria and/or haematuria could lead to serious renal injury.[8]

Acute blood pressure ranges from a mild disease to a lifethreatening process in pregnant patients. The clinical characteristics may vary with severe headaches, severe headaches, annoying mental conditions, acute strokes, severe upper right-hand abdominal pain, congestive heart failure or oliguria. This can only be inferred by execution in the vast majority of cases. The decision to continue to deliver after consulting medical and obstetric practitioners should be made.[16]

A major changeable risk factor for stroke is that of hypertension, with an estimated 51 percent of stroke deaths attributable globally to high systolic blood pressure. Timing, type of stroke, thrombolytic use, medically competitive conditions and pharmacological variables determine the management of stroke hypertension.

\section{METHODS}

The observational study was done among patients presented with hypertensive emergencies admitted under department of medicine, KIMS, Karad, from August 2018 to December 2018 on admission, detailed history was taken, and complete clinical examination was done. It was an observational study. The Present study was conducted after obtaining approval from institutional ethical committee. All the cases were enrolled in this study after taking their due consent.

\section{Inclusion Criteria}

1. $180 \mathrm{mmHg}$ systolic blood pressure and above or above $120 \mathrm{mmHg}$ diastolic blood pressure.

2. Evidence of injury whether clinically or in the laboratory.

\section{Criteria for Exclusion}

1. People below 18 years of age or older than 40 years of age

2. Hypertension caused by breastfeeding in patients with valvular heart disease.

\section{Diagnostic Criteria}

Hypertensive emergency treatment will be established. We obtained written informed consent in all cases to participate in the study.

\section{Data Collection Procedure}

This experiment included all patients who met the requirements for inclusion or omission. The permission was received from the clinicians and attendants included in the study to carry out the examinations and interventions required. A Proforma was prepared that included detailed history, medical review and appropriate research available at our hospital. A thorough diagnostic evaluation were undertaken, recognizing neurological deficiencies. For all cases, specific examinations such as haemoglobin, total white cell count, erythrocyte sedimentation level, daily urinalysis, blood glucose, blood urea, serum creatinine, serum electrolyte, serum lipid profile, chest X-ray, CT scan head, 
electrocardiography, fundoscopy, urinary albumin was conducted. The results were analysed to assess the aetiology, risk factors, and the pattern of clinical and radiological profile. A proper questionnaire was used to collect data from all the cases, and which was recorded in the form of tables and graphs. The data were analyzed using SPSS program version 21 software. The data was summarized and tabulated accordingly.

\section{RESULTS}

In this study, we found that the majority of cases with elevated hypertension were male $(56.25 \%)$, followed by $43.75 \%$ females. We found that most instances of elevated hypertension belonged to the age group of 56-65 years, (29, $16 \%)$, accompanied by $46-55 \%(26,16 \%)$ and $66-75 \%(16$, $66 \%$ ). The study participants had a median age of $57.41 \pm 14.12$ years.

Our analysis of their high blood pressure and diabetic diagnosis shows that most of the instances of hypertension $(67.70 \%)$ are identified and $12.5 \%$ were known for their diabetes mellitus and $4.16 \%$ for ischaemic heart disease. In the present study, they observed that most of the participants in the trials submitted headaches (81.25\%), accompanied by giddiness of $37.5 \%, 35.42 \%$ of those with headaches, $19.79 \%$ of cases of dyspnoea, limbo fatigue in $15.62 \%$, and oedema in $10.41 \%$ of the instances.

At briefing, they measured the systolic and diastolic blood pressure of all the study subjects. They observed that on admission the average systolic blood pressure was $183 \pm 24,7$ $\mathrm{mm} \mathrm{Hg}$ while on admission the average diastolic blood pressure was $99,68 \pm 18,03 \mathrm{mmHg}$.

We have encountered alleged brain imaging injuries (CT / MRI Brain). They observed that most patients had a haemorrhagic stroke (16.66\%), accompanied by $4.16 \%$ of intermittent ischaemic attacks and $4.16 \%$ with an ischaemic stroke.

\begin{tabular}{|c|c|c|}
\hline Gender & Number of Cases & Percentage \\
\hline Males & 54 & $56.25 \%$ \\
\hline Females & 42 & $43.75 \%$ \\
\hline Total & $\mathbf{9 6}$ & $\mathbf{1 0 0} \%$ \\
\hline \multicolumn{3}{|c|}{ Tables 1. Gender Distribution } \\
\hline
\end{tabular}

\begin{tabular}{|c|c|c|}
\hline Age Group & Number of Cases & Percentage \\
\hline$<25$ years & 1 & $1.04 \%$ \\
\hline $26-35$ & 7 & $7.29 \%$ \\
\hline $36-45$ & 12 & $12.5 \%$ \\
\hline $46-55$ & 25 & $26.04 \%$ \\
\hline $56-65$ & 28 & $29.16 \%$ \\
\hline $66-75$ & 16 & $16.66 \%$ \\
\hline$>76$ years & 7 & $7.29 \%$ \\
\hline Total & $\mathbf{9 6}$ & $\mathbf{1 0 0} \%$ \\
\hline \multicolumn{3}{|c|}{ Tables 2. Age Distribution } \\
\hline \multicolumn{3}{|c|}{}
\end{tabular}

\begin{tabular}{|c|c|c|}
\hline Blood Pressure & Mean & Standard Deviation \\
\hline Mean SBP & 183 & 24.7 \\
\hline Mean DBP & 99.68 & 18.03 \\
\hline \multicolumn{3}{|c|}{ Tables 3. Distribution of Study Subjects According to } \\
Their Blood Pressure \\
\hline
\end{tabular}

\begin{tabular}{|c|c|c|}
\hline Clinical Presentation & Number of Cases & Percentage \\
\hline Headache & 78 & $81.25 \%$ \\
\hline Giddiness & 36 & $37.5 \%$ \\
\hline Chest pain & 34 & $35.42 \%$ \\
\hline
\end{tabular}

\begin{tabular}{|c|c|c|}
\hline Dyspnoea & 19 & $19.79 \%$ \\
\hline Limb weakness & 15 & $15.62 \%$ \\
\hline Oedema & 10 & $10.41 \%$ \\
\hline Pallor & 11 & $11.45 \%$ \\
\hline \multicolumn{2}{|c|}{ Tables 4. Distribution of Study Subjects According to } \\
Their Clinical Presentation \\
\hline
\end{tabular}

\begin{tabular}{|c|c|c|}
\hline Brain Imaging Findings & Number of cases & Percentage \\
\hline Haemorrhagic stroke & 16 & $16.66 \%$ \\
\hline TIA & 4 & $4.16 \%$ \\
\hline Ischaemic stroke & 4 & $4.16 \%$ \\
\hline \multicolumn{2}{|c|}{ Tables 5. Distribution of Study Subjects according to } \\
their Brain Imaging Findings \\
\hline
\end{tabular}

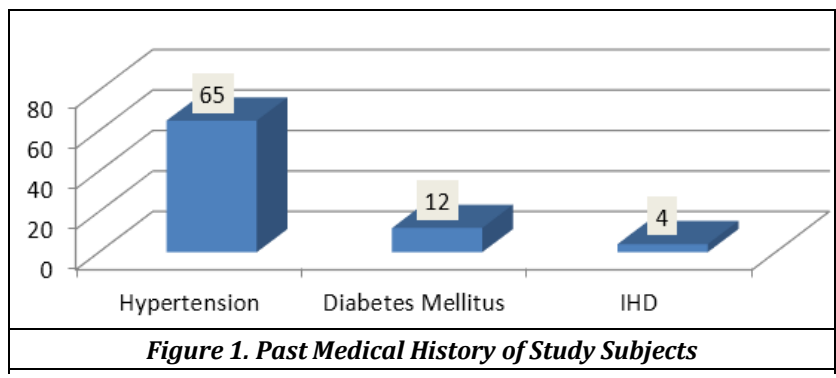

\section{DISCUSSION}

In the present study, we observed that majority of the cases presented with accelerated hypertension were males (56.25\%), followed by $43.75 \%$ female cases.

Hypertensive heart crises in the new clinical trial of tertiary healthcare. The number of men with high blood pressure is lower than that of females. 66 percent of these cases are persons. Some of them were Martin.[17] In their hypertensive disaster study, $55 \%$ of people in hypertensive emergencies are male was the potentially strongest in groups aged $56-65$ years $(29.16 \%)$, accompanied by age $46-55$ years $(26.16 \%)$ and $66-75$ years $(16.66 \%)$. This has been followed by $46-55 \%$. The average age for these subjects was $57.41 \pm 14.12$.

Hypertensive conditions and diabetic status have been assessed, we have observed that most of the cases were known for high blood pressure (67.70\%), 12.5\% for diabetes, and $4.16 \%$ for ischemic heart disease.

Garcia GM also noted that many (65.9\%) of the clinicians have already been treated with hypertension in their research. Increasingly, Zampanglione et al, ${ }^{[4]}$ notes that (92 percent) of their clinicians have experienced hypertensives. The study conducted by Martin et al. showed 26 percent of patients with diabetes mellitus.[17]

In this study, we found that most of the studied subjects had headache as their complaint $(81,25$ per cent) followed by 37,5 per cent giddiness, 35,42 per cent chest pain, 19,79 per cent dyspnoea, 15,62 per cent limb weakness and oedema among 10,41 per cent cases.

Martin et al[17] observed throughout their research that 48 per cent, 25 percent, and 18 per cent for their patients had symptoms of cognitive defects, dyspnoea, and chest pain. Zampaglione et al.[4] Numerous patients recorded chest pain $(27 \%)$ or neurological problems $(22 \%)$ in their report of dyspnoea. The present study evaluated the systemic and diastolic blood presences of all the study subjects, including hemiparesis (75\%), autism (16.6\%) and $\mathrm{vW}$. We found that on admission the average systolic blood pressure was 
$183 \pm 24,7 \mathrm{mmHg}$ whereas on admission the median diastolic blood pressure was $99,68 \pm 18,03 \mathrm{mmHg}$.

Martin et al,[17] respectively. A mean systolic blood pressure of $193 \pm 26 \mathrm{mmHg}$ and a median diastolic blood pressure of $129 \pm 12 \mathrm{mmHg}$ were recorded for their patients. They have encountered alleged brain imaging injuries (CT /MRI Brain). They observed that most patients had a haemorrhagic stroke (16.66\%), accompanied by $4.16 \%$ of intermittent ischaemic attacks and $4.16 \%$ with an ischaemic stroke.

The study shows a ventricular collapse (25 percent), acute ischemic stroke (39 percent) and an acute myocardial infarction ( 8 percent), respectively, intra-brain haemorrhage (17 percent). Zampaglione, other people.[4] In their study, target organ damage (23 percent), intracerebral and ischemic acute (24 percent) and ventricular dysfunction ( 4.5 percent) have been found in their patients.

With hypertensive encephalopathy there are unique medical and radiological results than in other types of hypertension. The subacute condition of hypertensive encephalopathy requires a number under days of increasing pressure. For example, for 0 days before presentation, all our patients had worsening headache and reported an increase in blood pressure.

Moreover, more extreme high blood levels, which are predisposed to intracranial haemorrhage and infarction, is induced by drugs or other sympathomimetic chemicals. Bleeds is probably due to sudden rises, typically at established vascular pathological shifts, in the hydrostatic forces, which overpower autoregulatory mechanisms. The infarction may be related to the extreme vasoconstriction caused to the sympathetic nerves along intracranial arteries by their direct effects.[18,19]

The outcome in the study showed an in-hospital mortality of $18.75 \%$ among these patients.

\section{CONCLUSIONS}

Hypertensive emergencies are most commonly seen in 45-65 years age group. The threat of acute organ damage due to high blood pressure is lower in the recorded hypertensives. The most common form of diagnosis is cognitive dysfunction. Intracerebral haemorrhage is the most severe hypertensive emergency.

\section{REFERENCES}

[1] Marso SP, Griffin BP, Topol EJ. Manual of cardiovascular medicine. $1^{\text {st }}$ edn. Lippincott Williams \& Wilkins 2000: p. 434-45.

[2] Bales A. Hypertensive crisis. How to tell if it's an emergency or an urgency. Postgrad Med 1999;105(5):119-26, 130.
[3] Vaidya CK, Ouellette JR. Hypertensive urgency and emergency. Hosp Physician 2007: p. 43-50.

[4] Zampaglione B, Pascale C, Marchisio $M$, et al. Hypertensive urgencies and emergencies. Prevalence and clinical presentation. Hypertension 1996;27(1):1447.

[5] Rehman SU, Basile JN, Vidt DG. Hypertension. In: Black HR, Elliott WJ, eds. A companion to Braunwald's Heart Disease. Saunders 2007: p. 517-24.

[6] Seiler B, Levitt EB. Heart disease in marathon runner: Is too much exercise a bad thing? University of Maryland Center. Science Daily 18 ${ }^{\text {th }}$ March, 2007.

[7] Volhard F, Fahr T. Die brightsche Nierenkranbeit: Klinik, Pathologie und Atlas. Berlin: Springer 1914.

[8] Bennett NM, Shea S. Hypertensive emergency: case criteria, socio-demographic profile and previous care of 100 cases. Am J Public Health 1988;78(6):636-40.

[9] Tisdale JE, Huang MB, Borzak S. Risk factors for hypertensive crisis: importance of out-patient blood pressure control. Fam Pract 2004;21(4):420-4.

[10] Barreto AD, Martin-Schild S, Hallevi H, et al. Thrombolytic therapy for patients who wake-up with stroke. Stroke 2009;40(3):827-32.

[11] Keith NM, Wagener HP, Barker NW. Some different types of essential hypertension: their course and prognosis. Am J Med Sci 1939;197:332-43.

[12] García-Peña $C$, Thorogood $M$, Reyes $S$, et al. The prevalence and treatment of hypertension in the elderly population of the Mexican Institute of Social Security. Salud Publica Mex 2001;43(5):415-20.

[13] Varon J, Marik PE. The diagnosis and management of hypertensive crises. Chest 2000;118(1):214-27.

[14] Rey E, LeLorier J, Burgess E, et al. Report of the Canadian Hypertension Society Consensus Conference: 3. Pharmacologic treatment of hypertensive disorders in pregnancy. CMAJ 1997;157(9):1245-54.

[15] Hickler RB. Hypertensive emergency: a useful diagnostic category. Am J Public Health 1988;78(6):623-4.

[16] Immink RV, van den Born BJ, van Montfrans GA, et al. Impaired cerebral autoregulation in patients with malignant hypertension. Circulation 2004;110(15):2241-5.

[17] Martin JF, Higashiama E, Garcia E, et al. Hypertensive crisis profile. Prevalence and clinical presentation. Arquivos Brasileiros de Cardiologia 2004;83(2):131-6, 125-30.

[18] Qureshi AI, Tuhrim S, Broderick JP, et al. Spontaneous intracerebral haemorrhage. $\mathrm{N}$ Engl $\mathrm{J}$ Med 2001;344(19):1450-60.

[19] Aguilar MI, Brott TG. Update in intracerebral haemorrhage. Neurohospitalist 2011;1(3):148-59. 